\title{
A MODEL FOR QUALITY MANAGEMENT IN A SUPPLY CHAIN WITH A RETAILER AND A MANUFACTURER
}

\author{
A. Ahmadi Javid ${ }^{1 *}$ and P. Hoseinpour ${ }^{2}$ \\ ${ }^{1}$ Department of Industrial Engineering \\ Amirkabir University of Technology, Iran \\ ahmadi_javid@aut.ac.ir \\ ${ }^{2}$ Department of Industrial Engineering \\ Amirkabir University of Technology, Iran \\ p.hoseinpour@aut.ac.ir
}

\begin{abstract}
This paper presents a model to study quality management in a supply chain system with one manufacturer and one retailer. The manufacturer invests in production quality, and the retailer compensates to improve service quality. The model is analysed using game theory.

\section{OPSOMMING}

'n Toevoerketting waar gehaltebestuur aangewend word deur 'n enkele vervaardiger en 'n enkele verbruiker word gemodelleer via die spelteorie. Die vervaardiger en die verbruiker neem deel aan besluitneming oor optimum befondsing van die bestuursaksies.
\end{abstract}

* Corresponding author 


\section{INTRODUCTION}

Quality has been defined as fitness for use, or the extent to which a product successfully serves the purpose of consumers [21]. Improving quality is an important factor in achieving competitive advantage for companies, and it is attended to extensively in today's fastpaced and increasingly competitive market [39]. Various aspects of quality have been investigated, two of which are product quality and service quality. A product, and the service offered to customers who buy the product, must meet or exceed customers' expectations. The emphasis on improving the quality of products and services has been increased by firms in reaction to enhanced competitive environments. In other words, product and service quality have been recognised as playing a crucial role in success and survival in today's competitive market.

Papers dealing with production and service quality are briefly considered below.

Efficient mechanisms are investigated in research into service quality $[18,19,31]$ in order to offer the best customer service. Retailers in a supply chain may be focusing on areas in their operations that might give them an advantage over their competitors. Therefore, investment in service quality is a way to enhance the efficiency of the entire supply chain. Several papers considering product quality deal with pay back-warranty contracts for the purpose of sharing costs caused by poor quality of various sections of the supply chain that can influence product quality positively or negatively $[6,32,33,25,20,5,44,34,2,3,4,40,24]$. Certain papers consider designing quality control processes. These papers present models consisting of determining batch size, order quantity, sampling size, randomly drawn from a lot, and critical value for accepting or rejecting the lot to minimise total cost $[38,29,8,36]$. Other papers study the relationship between quality and inventory control, and determine the lead time, order quantity, and probability of the production processes being out of control for the purpose of minimising the total aggregated cost of setup, ordering, adjustment of the production processes, and holding [14,43]. Some papers are related to the trade-off between price and quality for selection of a supplier by a customer $[37,23,16]$. More papers investigate the effect of price and quality on demand, and others how demand changes by variation of price, quality, brand diversity, and location of factory come about $[7,28,10,17,22,26,12,15,27,11,9,42,35]$. Finally there are papers that incorporate quality in designing supply chain networks $[13,1,41,30]$.

As reviewed above, there is little work in the literature that considers the relationship between product and service quality in a supply chain. This motivates us to present a model to consider product quality and service quality in a supply chain with a manufacturer and a retailer. The manufacturer invests in production quality and the retailer compensates to improve the service quality. The model is analysed by game theory.

The paper is organised as follows. The model is presented in Section 2. Sections 3 and 4 give the Nash and Stackelberg equilibriums of the model. Section 5 of the paper presents some interesting managerial results.

\section{MODELING}

The gross profits of the retailer and the manufacturer $\pi_{r}(a, q), \pi_{m}(a, q)$ are determined as:

$$
\begin{aligned}
& \pi_{r}(a, q)=\rho_{r} S(a, q)-a \\
& \pi_{m}(a, q)=\rho_{m} S(a, q)-q
\end{aligned}
$$

where the decision variables, parameters, and function $S(a, q)$ are defined below.

\section{(i) Decision variables:}

$a$ is the retailer's investment in improving service quality. 
$q$ is the manufacturer's investment in improving production quality.

(ii) Parameters:

$\rho_{m}$ is the manufacturer's marginal profit for each unit to be sold, and is a positive constant.

$\rho_{r}$ is the retailer's marginal profit for each unit to be sold, and is a positive constant.

(iii) Sale function:

$S(a, q)$ is a single period sale function.

In the above model, the following sale function is considered:

$$
S(a, q)=\alpha-\beta a^{-\gamma} q^{-\delta}, a \geq a_{0} \text { and } q \geq q_{0}
$$

where the parameters are interpreted as follows:

- $\quad \alpha$ is a positive constant and is the sale saturation asymptote. On the other hand, when either or both the production and service quality investments tend to infinity, $s(a, q)$ tends to the constant $\alpha$.

- $\quad \gamma$ is a positive constant, which is the elasticity of the service quality.

- $\delta$ is a positive constant, which is the elasticity of the production quality.

- $\quad \beta$ is a positive constant, and determines the impact of the production and service quality investments on market demand.

- $a_{0}$ is a lower bound for service quality, and is a non-negative number.

- $q_{0}$ is a lower bound for production quality, and is a non-negative number.

It should be noted that the parameters $a_{0}$ and $q_{0}$ somehow depend on each other - i.e. for every $q \geq q_{0}$, $a$ must be greater than $a_{0}$ such that $s(a, q) \geq 0$ for $a \geq a_{0}$ and $q \geq q_{0}$.

Considering

$$
S(a, q) \geq 0 \Leftrightarrow a \geq\left(\frac{\beta}{\alpha q^{\delta}}\right)^{\frac{1}{\gamma}},
$$

we should have $a \geq \bar{a}(q)$ with $\bar{a}(q)=\left(\frac{\beta}{\alpha q^{\delta}}\right)^{\frac{1}{\gamma}}$. The inequalities $q \geq q_{0}$ and $a \geq \bar{a}(q)$ imply $a \geq \sup _{q \geq q_{0}}(\bar{a}(q))$, and by observing that $\bar{a}(q)$ is non-decreasing with respect to $q$ we obtain $a \geq \bar{a}\left(q_{0}\right)$, which means that $a_{0}$ must satisfy $a_{0} \geq \bar{a}\left(q_{0}\right)$ to guarantee that $s(a, q)$ is nonnegative for $a \geq a_{0}$ and $q \geq q_{0}$. To preserve the full possible range of values for $a$, we suppose $a_{0}=\bar{a}\left(q_{0}\right)$.

In the next two sections the model is analysed for two scenarios. The first scenario is that the manufacturer and the retailer act sequentially, where the manufacturer is the leader and the retailer is the follower. This scenario is studied in Section 3 by using game theory, and the related equilibrium point, called the Stackelberg equilibrium, is obtained. The second scenario is that the manufacturer and the retailer act simultaneously. This scenario is considered in Section 4, and the associated equilibrium point, called the Nash equilibrium, is obtained. In the rest of the paper, for simplicity, we frequently use the auxiliary parameters $E, G, H, F$ defined below: 


$$
\begin{aligned}
& E:=q_{0}^{\delta+\gamma+1} \gamma^{\gamma} \beta^{-1} \delta^{-(1+\gamma)} \\
& G:=\frac{q_{0}}{\delta \alpha} \\
& H:=\left(\gamma^{-\gamma} \beta \alpha^{-(1+\gamma)} q_{0}^{-\delta}\right)^{\frac{1}{\gamma}} \\
& F:=\left(\beta^{1+\delta} \delta^{\delta \gamma} \gamma^{-\gamma(1+\delta)}\left(\alpha q_{0}^{\delta}\right)^{-(\delta+\gamma+1)}\right)^{\frac{1}{\gamma}}
\end{aligned}
$$

\section{SEQUENTIAL MOVE}

In this section we study the model for the first scenario that the manufacturer and the retailer sequentially move, where the manufacturer is leader and the retailer is follower. The leader first chooses the strategy $q$, and the follower then observes this decision and makes his own strategy choice $a$. In this scenario the model is analysed by obtaining the associated Stackelberg equilibrium point. To this end, we first find the optimal value of $a$ which optimises the retailer gross profit, and then by substituting it in the manufacturer's gross profit, we obtain the optimal value of $q$.

By defining $a_{r}^{*}(q)=\underset{a \geq a_{0}}{\operatorname{argmax}}\left(\pi_{r}(a, q)\right)$, the Stackelberg equilibrium point can be found by solving the following problem:

$$
\max _{q} \pi_{s t}=\pi_{m}\left(a_{r}^{*}(q), q\right)
$$

s.t.

$q \geq q_{0}$

The function $\pi_{r}(a, q)=\rho_{r} S(a, q)-a=\rho_{r}\left(\alpha-\beta a^{-\gamma} q^{-\delta}\right)-a$ is concave for $a \geq \bar{a}\left(q_{0}\right)$, so we have:

$$
a_{r}^{*}(q)=\max \left\{\bar{a}\left(q_{0}\right),\left(\frac{\gamma \rho_{r} \beta}{q^{\delta}}\right)^{\frac{1}{\gamma+1}}\right\} \text {. }
$$

By considering $a_{r}^{*}(q)$, the Stackelberg equilibrium point can be obtained by solving the following two problems:

$$
\begin{aligned}
& \max _{q} \pi_{m}=\rho_{m} \alpha-\rho_{m} \beta q^{-\delta}\left(\frac{\gamma \rho_{r} \beta}{q^{\delta}}\right)^{\frac{-\gamma}{1+\gamma}}-q \\
& \text { s.t. } \quad q \geq q_{0} \\
& \bar{a}\left(q_{0}\right) \leq\left(\frac{\gamma \rho_{r} \beta}{q^{\delta}}\right)^{\frac{1}{1+\gamma}} \\
& \max _{q} \pi_{m}=\rho_{m} \alpha-\rho_{m} \beta q^{-\delta}\left(\bar{a}\left(q_{0}\right)\right)^{-\gamma}-q \\
& \text { s.t. } q \geq q_{0} \\
& \text { (Problem 2) } \\
& \bar{a}\left(q_{0}\right) \geq\left(\frac{\gamma \rho_{r} \beta}{q^{\delta}}\right)^{\frac{1}{1+\gamma}}
\end{aligned}
$$

By solving Problems 1 and 2, and comparing their optimal objective values, we find the Stackelberg equilibrium $\left(q_{s}^{*}, a_{s}^{*}\right)$, which is presented in Table 1 under nine sets of conditions. In this table the following parameters are considered: 


$$
\begin{aligned}
& L=\left(\frac{1+\delta}{\delta}\right)\left(\delta \rho_{m} \alpha q_{0}^{\delta}\right)^{\frac{1}{1+\delta}}-\frac{\rho_{m}}{\gamma \rho_{r}}\left(\frac{\beta}{\alpha q_{0}^{\delta}}\right)^{\frac{1}{\gamma}}-q_{0}\left(\frac{\rho_{r}}{H}\right)^{\frac{1}{\delta}} \\
& M=\frac{\rho_{m}}{\gamma \rho_{r}}\left(\frac{\beta}{\alpha q_{0}^{\delta}}\right)^{\frac{1}{\gamma}}\left(1-\left(\frac{\rho_{r}}{H}\right)^{\frac{1}{1+\gamma}}\right)-q_{0}\left(1-\left(\frac{\rho_{r}}{H}\right)^{\frac{1}{\delta}}\right) \\
& N=\frac{\rho_{m}}{\gamma \rho_{r}}\left(\frac{\beta}{\alpha q_{0}^{\delta}}\right)^{\frac{1}{\gamma}}+q_{0}\left(\frac{\rho_{r}}{H}\right)^{\frac{1}{\delta}}-\left(\frac{1+\gamma+\delta}{\delta}\right)\left(\left(\frac{\rho_{\mathrm{m}} \delta}{1+\gamma}\right)^{\gamma+1}\left(\gamma \rho_{r}\right)^{-\gamma} \beta\right)^{\frac{1}{\delta+\gamma+1}}
\end{aligned}
$$

\begin{tabular}{|c|c|c|}
\hline$\#$ & Conditions & Stackelberg equilibrium \\
\hline 1 & $\begin{array}{l}(1+\gamma)^{-1-\gamma} \rho_{\mathrm{m}}{ }^{1+\gamma} \rho_{\mathrm{r}}{ }^{-\gamma}>E \\
(1+\gamma)^{\delta} \rho_{r}^{\delta+1} \rho_{\mathrm{m}}{ }^{-\delta}>F \\
\rho_{r}^{(\delta+1)} \rho_{m}^{-\delta}<F\end{array}$ & $\begin{array}{l}q_{s}^{*}=\left(\delta \rho_{m} \alpha q_{0}^{\delta}\right)^{\frac{1}{1+\delta}} \\
a_{s}^{*}=\beta^{\frac{1}{\gamma}}\left(\alpha q_{0}^{\delta}\right)^{\frac{-1}{\gamma}}\end{array}$ \\
\hline 2 & $\begin{array}{l}\rho_{r}>H \\
(1+\gamma)^{\delta} \rho_{r}^{\delta+1} \rho_{\mathrm{m}}^{-\delta} \leq F \\
L \leq 0\end{array}$ & $\begin{array}{l}q_{s}^{*}=\left(\delta \rho_{m} \alpha \mathbf{q}_{0}^{\delta}\right)^{\frac{1}{1+\delta}} \\
a_{s}^{*}=\beta^{\frac{1}{\gamma}}\left(\alpha \mathbf{q}_{0}^{\delta}\right)^{\frac{-1}{\gamma}}\end{array}$ \\
\hline 3 & $\begin{array}{l}\rho_{r}>H \\
(1+\gamma)^{\delta} \rho_{r}^{\delta+1} \rho_{\mathrm{m}}^{-\delta} \leq F \\
L \geq 0\end{array}$ & $\begin{array}{l}q_{S}^{*}=\left(\left(\gamma \rho_{r}\right)^{\gamma}\left(\alpha q_{0}^{\delta}\right)^{1+\gamma} \beta^{-1}\right)^{\frac{1}{\delta \gamma}} \\
a_{S}^{*}=\left(\gamma \rho_{r} \beta\right)^{\frac{1}{1+\gamma}} q_{s}^{* \frac{\delta}{1+\gamma}}\end{array}$ \\
\hline 4 & $\begin{array}{l}\rho_{m} \leq G \\
\rho_{r}<H\end{array}$ & $\begin{array}{l}q_{s}^{*}=q_{0} \\
a_{s}^{*}=\beta^{\frac{1}{\gamma}}\left(\alpha q_{0}^{\delta}\right)^{\frac{-1}{\gamma}}\end{array}$ \\
\hline 5 & $\begin{array}{l}(1+\gamma)^{-1-\gamma} \rho_{\mathrm{m}}{ }^{1+\gamma} \rho_{\mathrm{r}}{ }^{-\gamma}>E \\
\rho_{r}>H \\
\rho_{r}^{\delta+1} \rho_{m}^{-\delta} \geq F \\
N \leq 0\end{array}$ & $\begin{array}{l}q_{s}^{*}=\left(\left(\gamma \rho_{r}\right)^{\gamma}\left(\alpha q_{0}^{\delta}\right)^{1+\gamma} \beta^{-1}\right)^{\frac{1}{\delta \gamma}} \\
a_{s}^{*}=\beta^{\frac{1}{\gamma}}\left(\alpha q_{0}^{\delta}\right)^{-1}\end{array}$ \\
\hline 6 & $\begin{array}{l}(1+\gamma)^{-1-\gamma} \rho_{\mathrm{m}}^{1+\gamma} \rho_{r}^{-\gamma}>E \\
\rho_{r}>H \\
\rho_{r}^{\delta+1} \rho_{m}^{-\delta} \geq F \\
N \geq 0\end{array}$ & $\begin{array}{l}q_{\mathrm{s}}^{*}=\left(\left(\rho_{\mathrm{m}} \delta\right)^{\gamma+1}(1+\gamma)^{-(1+\gamma)}\left(\gamma \rho_{r}\right)^{-\gamma} \beta\right)^{\frac{1}{\delta+\gamma+1}} \\
a_{S}^{*}=\left(\gamma \rho_{r} \beta\right) \frac{1}{1+\gamma} q_{s}^{*} \frac{-\delta}{1+\gamma}\end{array}$ \\
\hline 7 & $\begin{array}{l}\rho_{r}>H \\
(1+\gamma)^{-1-\gamma} \rho_{\mathrm{m}}{ }^{1+\gamma} \rho_{r}^{-\gamma} \leq E \\
\rho_{r}^{(\delta+1)} \rho_{m}^{-\delta} \geq F \\
M \leq 0\end{array}$ & $\begin{array}{l}q_{s}^{*}=\left(\left(\gamma \rho_{r}\right)^{\gamma}\left(\alpha q_{0}^{\delta}\right)^{1+\gamma} \beta^{-1}\right)^{\frac{1}{\delta \gamma}} \\
a_{s}^{*}=\beta^{\frac{1}{\gamma}}\left(\alpha q_{0}^{\delta}\right)^{-1}\end{array}$ \\
\hline 8 & $\begin{array}{l}\rho_{r}>H \\
(1+\gamma)^{-1-\gamma} \rho_{\mathrm{m}}{ }^{1+\gamma} \rho_{r}^{-\gamma} \leq E \\
\rho_{r}^{\delta+1} \rho_{m}^{-\delta} \geq F \\
M \geq 0\end{array}$ & $\begin{array}{l}q_{s}^{*}=q_{0} \\
a_{s}^{*}=\left(\gamma \rho_{r} \beta\right)^{\frac{1}{1+\gamma}} q_{0} \frac{-\delta}{1+\gamma}\end{array}$ \\
\hline 9 & $\begin{array}{l}\rho_{m}>G \\
\rho_{r}<H \\
\rho_{r}^{\delta+1} \rho_{m}^{-\delta}<F\end{array}$ & $\begin{array}{l}q_{s}^{*}=\left(\delta \rho_{m} \alpha q_{0}^{\delta}\right)^{\frac{1}{1+\delta}} \\
a_{s}^{*}=\beta^{\frac{1}{\gamma}}\left(\alpha q_{0}^{\delta}\right)^{-1}\end{array}$ \\
\hline
\end{tabular}

Table 1: Stackelberg equilibrium point 


\section{SIMULTANEOUS MOVE}

In this section the model is investigated for the second scenario that the manufacturer and the retailer act simultaneously. In this scenario we can analyse the model by obtaining the Nash equilibrium point for the model. By defining

$a_{r}^{*}(q)=\underset{a \geq a_{0}}{\arg \max }\left(\pi_{r}(a, q)\right), q_{m}^{*}(a)=\underset{q \geq q_{0}}{\operatorname{argmax}}\left(\pi_{m}(q, a)\right)$

the Nash equilibrium point $\left(q_{N}^{*}, a_{N}^{*}\right)$ is the solution of the following system:

$$
\left\{\begin{array}{l}
a_{N}^{*}=a_{r}^{*}\left(q_{N}^{*}\right) \\
q_{N}^{*}=q_{m}^{*}\left(a_{N}^{*}\right) \\
a \geq a_{0}, q \geq q_{0}
\end{array}\right.
$$

The Nash equilibrium point, i.e. the solution of the above system, exists, and is given in Table 2 under four sets of conditions.

\begin{tabular}{|l|l|l|}
\hline$\#$ & Conditions & Nash equilibrium point \\
\hline 1 & $\begin{array}{l}\rho_{r} \leq H \\
\rho_{m} \leq G\end{array}$ & $\begin{array}{l}q_{N}^{*}=q_{0} \\
a_{N}^{*}=\beta^{\frac{1}{\gamma}}\left(\alpha q_{0}^{\delta}\right)^{\frac{-1}{\gamma}}\end{array}$ \\
\hline 2 & $\begin{array}{l}\rho_{m}>G \\
\rho_{r}^{\delta+1} \rho_{m}{ }^{-\delta} \leq F\end{array}$ & $\begin{array}{l}q_{N}^{*}=\left(\rho_{m} \delta \alpha q_{0}^{\delta}\right)^{\frac{1}{1+\delta}} \\
a_{N}^{*}=\beta^{\frac{1}{\gamma}}\left(\alpha q_{0}^{\delta}\right)^{-1} \gamma\end{array}$ \\
\hline 3 & $\begin{array}{l}\rho_{r}>H \\
\rho_{m}^{1+\gamma} \rho_{r}^{-\gamma} \leq E\end{array}$ & $\begin{array}{l}q_{N}^{*}=q_{0} \\
a_{N}^{*}=\left(\gamma \rho_{r} \beta\right)^{\frac{1}{1+\gamma}} q_{0}^{\frac{-\delta}{1+\gamma}}\end{array}$ \\
\hline 4 & $\begin{array}{l}\rho_{r}{ }^{\delta+1} \rho_{m}{ }^{-\delta}>F \\
\rho_{m}^{1+\gamma} \rho_{r}^{-\gamma}>E\end{array}$ & $\begin{array}{l}q_{N}^{*}=\left(\left(\delta \rho_{m}\right)^{1+\gamma}\left(\rho_{r} \gamma \beta\right)^{-\gamma}\right)^{1+\delta+\gamma} \\
a_{N}^{*}=\left(\gamma \rho_{r} \beta\right)^{\frac{1}{1+\gamma}} q_{N}^{*} \frac{-\delta}{1+\gamma}\end{array}$ \\
\hline
\end{tabular}

Table 2: Nash equilibrium point

\section{CONCLUSIONS AND COMMENTS}

In Sections 3 and 4, the model of Section 2 is analysed by game theory for the two scenarios of sequential move and simultaneous move. Tables 1 and 2 respectively present the Stackelberg equilibrium point for the scenario of sequential move, and the Nash equilibrium point for the scenario of simultaneous move. These results help both manufacturer and retailer to choose suitable strategies for their investment values on product and service quality. Moreover, from these tables it may be seen how changing the parameters of the model affects the investment values in each scenario. For example, for the parameters $\rho_{m}$ and $\rho_{r}$ we have: 


$$
\begin{aligned}
& \frac{\partial a_{S}^{*}}{\partial \rho_{m}}=0, \frac{\partial q_{s}^{*}}{\partial \rho_{m}} \geq 0 \\
& \frac{\partial a_{s}^{*}}{\partial \rho_{r}} \geq 0, \frac{\partial q_{s}^{*}}{\partial \rho_{r}} \geq 0 \text { (except for Case 6 in Table 1) } \\
& \frac{\partial a_{N}^{*}}{\partial \rho_{m}}=0, \frac{\partial q_{N}^{*}}{\partial \rho_{m}} \geq 0 \\
& \frac{\partial a_{N}^{*}}{\partial \rho_{r}} \geq 0, \frac{\partial q_{N}^{*}}{\partial \rho_{r}} \leq 0
\end{aligned}
$$

These show that the manufacturer's investments in quality, i.e. $q_{N}^{*}$ and $q_{s}^{*}$, positively depend on its marginal profit $\rho_{m}$, and that the retailer's investments in service quality, i.e. $a_{N}^{*}$ and $a_{s}^{*}$, positively depend on its marginal profit $\rho_{r}$. In other words, if they wish to increase their marginal profits, they cannot decrease their investments in quality. In addition, $\rho_{r}$ affects the manufacturer's investments, while $\rho_{m}$ does not affect the retailer's investments. This means that if the manufacturer decides to increase its marginal profit, there is no need for an increment in the retailer's investment in service quality in both scenarios. However, if the retailer increases its marginal profit, in the scenario of simultaneous move the manufacturer should not increase its investment in production quality, while in the scenario of sequential move the retailer cannot decrease its investment except for Case 6 in Table 1.

\section{REFERENCE}

[1] Bachlausa, M., Tiwarib, M.K. \& Chan, F.T.S. 2009. Multi-objective resource assignment problem in a product-driven supply chain using a Taguchi-based DNA algorithm, International Journal of Production Research, 47(9), pp 2345-2371.

[2] Baiman, S., Fischer, P.E. \& Rajan, M.V. 2000. Information, contracting, and quality costs, Management Science, 46(6), pp 776-789.

[3] Baiman, S., Fischer, P.E. \& Rajan, M.V. 2001. Performance measurement and design in supply chains, Management Science, 47(1), pp 173-188.

[4] Baiman, S., Netessine, S. \& Kunreuther, H. 2003. Procurement in supply chains when the end-product exhibits the weakest link property, Working paper, the Wharton School, University of Pennsylvania.

[5] Balachandran, K.R. \& Radhakrishnan, S. 2005. Quality implications of warranties in supply chain, Management Science, 51(8), pp 1266-1277.

[6] Barber, B.M. \& Darrough, M.N. 1996. Product reliability and firm value: The experience of American and Japanese automakers, Journal of Political Economy, 104(5), pp 1084-1099.

[7] Chambers, C., Kouvelis, P. \& Semple, J. 2006. Quality-based competition, profitability, and variable costs, Management Science, 52(12), pp 1884-1895.

[8] Cheung, K.L. \& Leung, K.F. 2000. Coordinating replenishments in a supply chain with quality control considerations, Production Planning \& Control, 11(7), pp 697705.

[9] Choudhary, V., Ghose, A., Mukhopadhyay, T. \& Rajan, U. 2005. Personalized pricing and quality differentiation, Management Science, 51(7), pp 1120-1130.

[10] Degryse, H. 1996. On the interaction between vertical and horizontal product differentiation: An application to banking, The Journal of Industrial Economics, 44(2), pp 169-186.

[11] Doraszelskiw, U. \& Draganskaz, M. 2006. Market segmentation strategies of multiproduct firms, The Journal of Industrial Economics, LIV(1), pp 125-149.

[12] Economides, N. 1989. Quality variations and maximal variety differentiation, Regional Science and Urban Economics, 19, pp 21-29.

[13] El Maraghy, H.A. \& Majety, R. 2008. Integrated supply chain design using multi- 
criteria optimization, International Journal of Advance Manufacturing Technology, 37, pp 371-399.

[14] El Saadany, A.M.A. \& Jaber, M.Y. 2008. Coordinating a two-level supply chain with production interruptions to restore process quality, Computers \& industrial Engineering, 54, pp 95-109.

[15] Gans, N. 2002. Customer loyalty and supplier quality competition, Management Science, 48(2), pp 207-221.

[16] Ghodsypour, S.H. \& O'Brien,C.. 2001. The total cost of logistics in supplier selection, under conditions of multiple sourcing, multiple criteria and capacity constraint, International Journal of Production Economics, 73, pp 15-27.

[17] Hall, J.M. \& Porteus, E.L. 2000. Customer service competition in capacitated systems, Manufacturing \& Service Operations Management, 2, pp 144-165.

[18] Hosanagar, K., Krishnan, R. \& Choudhary, V. 2005. Pricing and resource allocation in caching services with multiple levels of quality of service, Management Science, 51(12), pp 1844-1859.

[19] Hsu, V.N., Xu, S.H. \& Jukic, B. 2008. Optimal scheduling and incentive compatible pricing for a service system with quality of service guarantees, Manufacturing \& Service Operations Management, 11(3), pp 375-396.

[20] Jarrell, G. \& Peltzman, S. 1985. The impact of recalls on the wealth of sellers, Journal of Political Economy 43(3), pp 467-473.

[21] Juran, J.M., Gryna, F.M.J. \& Bingham, R.S. 1974. Quality control handbook ( ${ }^{\text {rd }}$ ed.), McGraw-Hill Book Co, New York, NY.

[22] Kim, K. \& Lin, D. 2006. Optimization of multiple responses considering both location and dispersion effects, European Journal of Operational Research, 169, pp 133-145.

[23] Lee, M.S., Lee, Y.H. \& Jeong, C.S. 2003. A high-quality-supplier selection model for supply chain management and ISO 9001 system, Production Planning \& Control, 14(3), pp 225-232.

[24] Lim, W.S. 2001. Producer-supplier contracts with incomplete information, Management Science, 47(5), pp 709-715.

[25] Mann, D.P. \& Wissink, J.P. 1990. Money-back warranties vs. replacement warranties: A simple comparison, American Economic Review, 80(2), pp 432-436.

[26] Melumad, N.D. \& Ziv, A. 2004. Reduced quality and an unlevel playing field could make consumers happier, Management Science, 50(12), pp 1646-1659.

[27] Mukhopadhyay, S.K. \& Setaputra, R. 2007. A dynamic model for optimal design quality and return policies, European Journal of Operational Research, 180, pp 11441154.

[28] Piga, C. \& Poyago-Theotoky, J. 2005. Endogenous R\&D spillovers and locational choice, Regional Science and Urban Economics, 35, pp 127- 139.

[29] Porteus, E.L. 1990. The impact of inspection delay on process and inspection lot sizing, Management Science, 36, pp 999-1007.

[30] Ramudhin, A., Alzaman, C. \& Bulgak, A.A. 2008. Incorporating the cost of quality in supply chain design, Journal of Quality in Maintenance Engineering, 14(1), pp 71-86.

[31] Ren, Z.J., Zhou \& Y.P. 2008. Call center outsourcing: Coordinating staffing level and service quality, Management Science, 54(2), pp 369-383.

[32] Reyniers, D.J. \& Tapiero, C. 1995a. The delivery and control of quality in supplierproducer contracts, Management Science, 41(10), pp 1581-1589.

[33] Reyniers, D.J. \& Tapiero, C. 1995b. Contract design and the control of quality in a conflictual environment, European Journal of Operational Research, 82(2), pp 373382.

[34] Rupp, N.G. 2004. The attributes of a costly recall: Evidence from the automotive industry, Rev. Ind.Org, 25(5), pp 21-44.

[35] Sanjo, Y. 2007. Hotelling's location model with quality choice in mixed duopoly, Economics Bulletin, 18(2), pp 1-11.

[36] Starbird, S.A. 1997. Acceptance sampling, imperfect production and the optimality of zero defects, Naval Research Logistics Quarterly, 44, pp 515-530.

[37] Tagaras, G. \& Lee, H.L. 1996. Economic models for vendor evaluation with quality cost analysis, Management Science, 42, pp 1531-1543.

[38] Tapiero, C.S. 2007. Consumers risk and quality control in a collaborative supply 
chain, European Journal of Operational Research, 182, pp 683-694.

[39] Tellis, G.J. \& Johnson, J. 2007. The value of quality, Marketing Science, 26(6), pp 758-773.

[40] Tunca, T.I. \& Zenios, S.A. 2006. Supply auctions and relational contracts for procurement, Manufacturing \& Service Operations Management, 8(1), pp 43-67.

[41] Wang, W. \& Wang, J. 2003. Research on approach of supply chain planning with quality control in an OW environment, Proceeding of the $42^{\text {nd }}$ IEEE Conference on Decision and Control.

[42] Xu, X. 2009. Optimal price and product quality decisions in a distribution channel. Management Science, 55(8), pp 1347-1352

[43] Yang, J.S. \& Pan, J.C. 2004. Just-in-time purchasing: An integrated inventory model involving deterministic variable lead time and quality improvement investment, International Journal of Production Research, 42(5), pp 853-863.

[44] Zhu, K., Zang, R.Q. \& Tsung, F. 2007. Pushing quality along the supply chain, Management Science, 53(3), pp 421-436. 
http://sajie.journals.ac.za 